\title{
A tutela penal ambiental e a (in)evolução do meio ambiente como bem jurídico: um estudo de caso do tipo penal do artigo 38 da Lei no 9605/98
}

\author{
The environmental criminal tutelage and the (in)evolution of the \\ environment as a legal good: a case study of the crime described \\ on the article 38 of Law No. 9605/98
}

\author{
SÉRGIO AUGUSTIN \\ Doutor em Direito (UFPR). Coordenador do PPGDIR-UCS. Juiz de Direito do RS
}

\begin{abstract}
RESUMO: A Constituição Federal brasileira estabelece que o ambiente é um direito fundamental e como tal deve ser protegido, para esta e futuras gerações. Estabelece, ainda, que os crimes praticados contra o meio ambiente, que se tornam cada dia danosos e impactantes ao meio ambiente como um todo, devem ser coibidos. A legislação infraconstitucional penal ambiental, em especial a Lei $\mathrm{n}^{\circ}$ 9.605/98, busca regulamentar o texto constitucional, e estabelece tipos penais com a finalidade de proteção destes bens jurídicos. Neste artigo, investiga-se a aplicabilidade de um dispositivo específico, art. 38 da Lei dos Crimes Ambientais, que busca a proteção da floresta enquanto área de preservação permanente. A partir de um processo criminal que resultou de uma denúncia por crime ambiental, analisa-se o tipo penal previsto no referido art. 38 .

Palavras-chave: Bem jurídico ambiental. Crime ambiental. Defesa do meio ambiente.
\end{abstract}

ABSTRACT: The Brazilian Federal Constitution establishes that the environment is a fundamental right and as such should be protected for this and future generations. Establishes also that the crimes against the environment, which daily become harmful and impactful to all nature, should be restrained. The environmental criminal constitutional legislation, especially the Law 9.605/98, seeks to regulate the constitution and establishing criminal offenses for the purpose of protecting these legal assets. In this paper we investigate the applicability of a specific device, art. 38 of the Environmental Crimes Law, which seeks to protect the forest while it is a permanent preservation area. From a criminal case that has resulted from a complaint by environmental crime, it is analyzed the criminal offense referred to in the already mentioned art. 38 .

Keyword: Environmental legal good. Environmental crime. Environmental protection.

\section{INTRODUÇÃO}

Este estudo objetiva a análise de uma imputação penal ambiental onde a conduta de pessoas físicas e jurídicas, no interior do Rio Grande do Sul, resultou em absolvição, pela Justiça Federal, após o enquadramento, entre outras condutas, na prevista no artigo 38 da Lei $n^{-}$ 9.605/98, conhecida como Lei de Crimes Ambientais.

Segundo a peça acusatória, os denunciados teriam extraído recursos minerais sem prévia autorização do órgão ambiental, e teriam igualmente realizado a extração sem autorização da União, configurando-se delito de usurpação.

A denúncia revela que os autores do crime ambiental teriam destruído e danificado área de preservação permanente (APP), gerando-se danos ao meio ambiente, em área classificada como de "topo de morro", o que enquadra os autores nos crimes previstos nos artigos 38 e 55, c/c 15, II, “a”, da Lei no 9.605/98.

Inicialmente, analisa-se a consagração do meio ambiente como direito fundamental na Constituição Federal. Indispensável, ainda, o que será apresentado à frente, a exposição da proteção das áreas de preservação permanente, eis que uma das modalidades de espaço territorial com proteção especial na legislação brasileira. Nesta linha, registra-se que a Lei Maior fez a previsão expressa da criminalização para a efetiva tutela do direito fundamental ao meio ambiente a ser protegido.

Em seguida, enfrenta-se a possibilidade ou não de definição de bem jurídico protegido pelo Direito Penal e Processo Penal, na esfera ambiental, com os problemas 
daí decorrentes, em especial o caráter acessório deste frente o Direito Administrativo. Sem esquecer, claro, do caráter simbólico.

Após, a proteção das áreas de preservação permanente, mesmo em formação, que deflui da interpretação do artigo 38 da Lei no 9605/98, tipo penal que possui um elemento normativo presente, qual seja, a "floresta". Não são protegidas todas as florestas, mas somente aquelas de preservação permanente, definidas por lei.

Ao final, busca-se tecer comentários, mesmo que não conclusivos, a respeito da hermenêutica jurídica do tipo penal do artigo 38 da Lei no 9605/98, e sobre o enfretamento da questão pelo Superior Tribunal de Justiça, dada a necessidade de evitar retrocesso ambiental e eventual afronta à proporcionalidade em relação aos demais tipos penais de proteção ambiental previstos na legislação já referida.

Ao cabo, será analisada a decisão do fato delituoso que compõe a denúncia descrita acima, sem ingressar no mérito da decisão já proferida no processo verdadeiro.

\section{DO PANORAMA CONSTITUCIONAL DA PROTEÇÃO DO MEIO AMBIENTE PROTEGIDO}

A Constituição Federal apresenta vários elementos ordenadores, porém, um em especial: a unidade argumentativa. Trata-se de um remédio aos efeitos desagregadores dos excessos legislativos contemporâneos. A Constituição deve ser recepcionada como um direito superior, vinculativo, inclusive para as casas legislativas.

Deve o panorama constitucional vincular não apenas os atores, mas todos os envolvidos, desde o legislador, integrantes do Judiciário e também sociedade civil. Apresenta-se todo este panorama de leis e princípios como unidade da Constituição no Estado Democrático de Direito, com a presença simultânea de princípios, regras, direitos fundamentais, separação de poderes, no mínimo.

Esta unidade está refletida na opção do constituinte em definir o meio ambiente como bem jurídico fundamental. Em consequência, todos os meios de tutela do ambiente estão previstos constitucionalmente: a esfera administrativa, a esfera judicial civil, reparatória ou não, eis que é possível a tutela do meio ambiente com as ações constitucionalmente descritas (ação popular e ação civil pública, por exemplo) e a esfera judicial penal, até mesmo com a possibilidade - apesar de posições doutrinárias em contrário ${ }^{1}$ - de penalização da pessoa jurídica pelo crime ambiental ${ }^{2}$.
A despeito de vários dispositivos consagrarem o direito ao meio ambiente ecologicamente equilibrado como um direito fundamental, com titularidade difusa, com aplicação imediata e com a impossibilidade de modificação, eis que relacionado como cláusula pétrea, é graças à unicidade já referida que o bem jurídico "meio ambiente" está em harmonia constitucional.

O direito fundamental ao meio ambiente estabelece o dever genérico de defesa e preservação, assim como a limitação da exploração da propriedade. Diversas são as obrigações positivas impostas não só à sociedade civil, mas, principalmente, ao poder público. Caberá, assim, a este, o dever de responsabilização integral do causador de dano ambiental, e coibir toda e qualquer ameaça, mesmo que futura. Deverá tomar medidas de proteção aos espaços territoriais e seus componentes. Daí o surgimento de áreas de preservação permanente, assim como "reservas legais", com a vedação constitucional de qualquer utilização dos referidos espaços territoriais classificados como tal (áreas de preservação permanente), de modo a garantir a manutenção dos atributos que justifiquem sua proteção e a obrigação de restaurar imediatamente a integridade ecológica eventualmente atingida, sob pena de penalização e reparação do dano (nem sempre é possível reparar, também por isso a alternativa da multa), cumulativamente.

Portanto, todos os meios de tutela, instrumentos, garantias, direitos fundamentais postos à disposição da atual sociedade e de futuras gerações.

\section{A FUNÇÃO DO DIREITO PENAL NA PROTEÇÃO AOS BENS JURÍDICOS}

A função de proteção de bens jurídicos pode se apresentar aparentemente tranquila em diversos manuais, em especial, naqueles que tratam da tutela penal ambiental.

Para Maria Dolores Serrano Tárraga e demais professores do Departamento de Derecho Penal y Criminologia da Universidad Nacional de Madrid, "la función fundamental del Derecho penal contemporâneo es la pretección de bienes jurídicos"3.

Porém, ausente o consenso quanto à função do Direito Penal contemporâneo, e sequer quanto ao âmbito de sua atuação, restando uma discórdia doutrinária a respeito deste aspecto jurídico.

Para análise da situação, tomaremos os ensinamentos de Claus Roxin, em especial o conteúdo de suas manifestações em evento na Colômbia, que resultaram na publicação traduzida por André Luís Callegari e Nereu José Giacomolli. 
Primeiro, não há consenso sequer quanto à existência de um conceito de bem jurídico: "Hirsch afirma que 'não existe' um conceito de bem jurídico predeterminado pelo legislador. $\mathrm{O}$ conceito de bem jurídico não é um princípio idôneo para limitar o Direito Penal.".4.

E prossegue Roxin, analisando um segundo doutrinador: "Stratenwerth remete às múltiplas e variadas definições do bem jurídico na literatura para logo afirmar que 'uma definição material universal de bem jurídico' equivaleria a 'deixar o círculo quadrado', isto é, seria impossível. Ademais, ele sustenta que o motivo para a elaboração de um tipo penal não é a proteção de bens jurídicos, mas a inconveniência de um comportamento"s.

E, dando sequência, analisando um terceiro autor,Roxin afirma: "finalmente, Jakobs observa, desde um princípio, que a função do Direito penal é a confirmação da vigência da norma, e não a proteção de bens jurídicos. O fato punível é a negação da norma pelo autor, e a pena tem como significado que a 'a afirmação do autor não é determinante e que a norma segue vigendo inalteradamente".

Entretanto, há autores que defendem a ideia da existência de bens jurídicos a serem protegidos, e esta é a função do Direito Penal. Roxin cita alguns, como Hassemer e Schümemann, e a seguir parte de que as fronteiras da autorização de intervenção penal devem resultar de uma social do Direito Penal: "a função do Direito Penal consiste em garantir a seus cidadãos uma existência pacífica, livre e socialmente segura, sempre e quando estas metas não possam ser abraçadas com outras medidas político-sociais que afetem em menor medida a liberdade dos cidadãos"6.

O enfrentamento doutrinário é de pouca relevância para a análise da situação concreta que se propõe este texto. Porém, importantes são as conclusões quanto aos limites impostos que o conceito de bem jurídico traça ao legislador. Estes sim, relacionados, contribuirão com a análise do tipo penal em comento.

Roxin esboça algumas conclusões. A primeira, não admitindo uma norma jurídico-penal por motivações ideológicas ou que atentem contra os direitos fundamentais e humanos. A segunda, utilizando-se de um exemplo de porte de entorpecente, é no sentido de que a transcrição do objeto da lei não fundamenta um bem jurídico.

Como terceira e quarta conclusão, estabelece o referido autor que atentar contra a moral ou contra a dignidade humana não justifica uma norma penal ou significa, de pronto, uma lesão a um bem jurídico. "A proteção de sentimento somente pode ter-se [sic.] como proteção de bens jurídicos tratando-se de sentimentos de ameaça"'. A consciente autolesão, não havendo déficit de autonomia, em uma hipótese de suicídio, da mesma forma, não admite uma punição, em razão da proteção de bens jurídicos ter por objeto a proteção perante outra pessoa, não frente a si mesmo.

Importante a sétima conclusão, relativa às leis penais simbólicas, para a situação em comento. Esclarece Roxin que "não buscam a proteção de bens jurídicos". São “tipos penais simbólicos as leis que não são necessárias para o asseguramento de uma vida em comunidade e que, ao contrário, perseguem fins que estão fora do Direito Penal, como o apaziguamento do eleitor ou uma apresentação favorecedora do Estado".

Como oitava e nona conclusões, estão descritos pelo mesmo autor que a regulação de tabus e os objetos de proteção de uma abstração incompreensível, não devem ser aceitos como bens jurídicos.

Importante é estabelecer que os bens jurídicos, assim, são reais ou mesmo são finalidades necessárias para uma vida digna. Vida esta considerada individual ou socialmente. Porém, é imprescindível, para reconhecimento do princípio do bem jurídico que exista um sistema estatal com funcionamento e fundado nos mesmo objetivos.

Depois de tais conclusões, na crítica que Roxin faz ao colega Stratenwerth, quanto aos bens ambientais, temos a seguinte afirmativa:

\begin{abstract}
Não obstante, concordo, afinal de contas, em um ponto essencial com Stratenwerth. Ele deseja incorporar no âmbito de atuação do Direito Penal, a proteção de animais e a proteção da sobrevivência das futuras gerações. Eu também considero que o mau-trato de animais ou o extermínio de espécies animais devem ser penalizados da mesma forma que, por exemplo, a destruição que prejudica eficazmente a vida das futuras gerações. Poderse-ia pensar que estes dois eventos contradizem a ideia de proteção de bens jurídicos, pois o atentado contra os animais e as futuras gerações não afeta necessariamente a coexistência pacífica dos homens que vivem atualmente. Sem embargo, por isso não se necessita renunciar ao princípio de proteção de bens jurídicos como o quer Strantenwerth. Somente há que ampliá-lo, fazendo extensivo o contrato social, mais além do círculo dos homens que vivem atualmente, a outras criaturas e às gerações futuras ${ }^{8}$.
\end{abstract}

Portanto, o meio ambiente saudável, para esta e futuras gerações, é um bem jurídico a ser protegido pelo Direito Penal.

Poderá ocorrer divergências teóricas, não se admitindo um conceito para bem jurídico, ou talvez sim, mas hoje a legislação ambiental brasileira está 
fundada em tais premissas teóricas. Ou seja, está posta como função do Direito Penal a proteção de bens jurídicos.

Difícil um consenso a respeito da função do Direito Penal, talvez possam ser admitidas outras. E, mesmo fazendo a ressalva de que esta ideia tem sido posta em dúvida, afirmam os autores Maria Dolores Serrano Tárraga, Alfonso Serrano Maíllo e Carlos Vázquez González que:

El Derecho penal cumple uma importante fución de afirmación de los valores más importantes de uma sociedad. Aunque es problable que em lãs sociedades contemporâneas predomine el consenso - esto es que lamayor parte de la población está relativamente de acuerdo sobre aquellos valores más importantes, incluídos los próprios delincuentes -, no cabe duda de que existen disputas sobre algunos de ellos. Estas disputas puedem centrarse em comportamientos concretos, y puede acontecer que determinados grupos pretendan que la ley refurtce su postura, esto es los intereses y valores que consideram fundamentales $-y$, por ende, su posición social ${ }^{9}$.

Apresentado este panorama doutrinário, passamos à análise do tipo penal em estudo, que fundou a acusação e tem a descrição na denúncia formulada pelo órgão ministerial, reitera-se, já julgada.

\section{O TIPO PENAL DO ARTIGO 38 DA LEI № 9605/98 E SEUS ELEMENTOS INFORMATIVOS}

Vale lembrar que a denúncia narra que os acusados teriam destruído e danificado área de preservação permanente (APP), gerando-se danos ao meio ambiente, em área classificada como de "topo de morro", o que enquadra os autores nos crimes previstos nos artigos 38 e 55, c/c 15, II, "a", da Lei no 9.605/98.

Não se pretende fazer um longo resgate histórico da legislação protetiva das florestas, pois esta remonta ao século XVI, com a ocupação portuguesa. Porém, a Constituição Federal de 1934, com a finalidade de proteção, atribuiu expressamente à União a competência privativa de legislar a respeito da matéria. No primeiro Código Florestal brasileiro, instituído pelo Decreto no 23.793, também do ano de 1934, já no seu primeiro artigo, estabeleceu o legislador que "as florestas existentes no território nacional, consideradas em conjunto, constituem bem de interesse comum a todos os habitantes do país, exercendo-se os direitos de propriedade com as limitações que as leis, em geral, e especialmente este Código, estabelecem".
A seguir, sem deixar de registrar que inúmeros textos legais também estabeleceram proteções às florestas brasileiras, mesmo que não tenham dado resultado prático, o Código Florestal de 1965 avançou e equiparou em grau de importância as florestas e as demais formas de vegetação. Reconheceu de utilidade as terras que às revestem, indicando que são áreas de preservação permanente, as chamadas APPs, com a função de proteção dos recursos hídricos, do entorno geológico, da biodiversidade que nela existe, buscando, assim, a proteção e a regeneração. Função ecológica, com a finalidade de proteção, mas também de recuperação, se eventualmente atingida pela ação humana danosa ou impactante.

A Lei Federal no 12.651, de 25 de maio de 2012, novo Código Florestal brasileiro, após longa discussão no parlamento, disciplina em seu artigo segundo que "as florestas existentes no território nacional e as demais formas de vegetação nativa, reconhecidas de utilidade às terras que revestem, são bens de interesse comum a todos os habitantes do País, exercendo-se os direitos de propriedade com as limitações que a legislação em geral e especialmente esta Lei estabelecem". Em seguida, no artigo terceiro, estabelece definições, entre elas o que é uma área de preservação permanente: "II - Área de Preservação Permanente - APP: área protegida, coberta ou não por vegetação nativa, com a função ambiental de preservar os recursos hídricos, a paisagem, a estabilidade geológica e a biodiversidade, facilitar o fluxo gênico de fauna e flora, proteger o solo e assegurar o bem-estar das populações humanas".

As áreas de proteção permanente (APP) são, portanto, área com a condição de espaço territorialmente protegido, com amparo constitucional, além da proteção legislativa no referido código.

Diante da importância da função para o ambiente das áreas de preservação permanente, resta claro que a conduta de quem destrói ou danifica esta área protegida está ofendendo um bem jurídico protegido pela legislação ambiental, podendo incidir em crime.

A Lei $\mathrm{n}^{\circ}$ 9.605/98, que estabelece sanções penais e administrativas às condutas e atividades lesivas ao meio ambiente, fez a previsão, no artigo 38, que é crime apenado com detenção de um a três anos, "destruir ou danificar floresta considerada de preservação permanente, mesmo que em formação, ou utilizá-la com infringência das normas de proteção".

O objeto material da conduta são florestas de preservação permanente, formadas ou ainda em formação. Ganha especial relevo, portanto, a definição do elemento normativo "floresta, ainda que em formação" para incidência do tipo penal previsto no art. 38 . 
Não são protegidas neste tipo penal todas as florestas, mas somente as florestas de preservação permanente.

A definição aceita por considerável parcela da doutrina do elemento normativo floresta é a contida no Anexo I da Portaria 486-P, de 28 de outubro de 1986, do antigo IBDF, sucedido pelo IBAMA, que, no seu item 18, conceitua floresta como "a formação arbórea densa, de alto porte, que recobre área de terra mais ou menos extensa". Utilizam este conceito Vladimir Passos de Freitas e Gilberto Passos de Freitas ${ }^{10}$ e Luís Paulo Sirvinskas ${ }^{11}$.

Passamos, por fim, antes das conclusões quanto ao caso concreto, à análise das manifestações do Superior Tribunal de Justiça (STJ) a respeito do artigo 38 da Lei no 9.605/98.

\section{O ENFRENTAMENTO PROCESSUAL PENAL PELO SUPERIOR TRIBUNAL DE JUSTIÇA - STJ}

Cabe destacar, inicialmente, que a jurisprudência do Superior Tribunal de Justiça, quanto às áreas de preservação permanente (APP), tanto quanto ao dever de manutenção ou reparação, é reiterada no sentido de que se estabelece uma obrigação propter rem e endereçada a todos. O proprietário ou possuidor, mesmo que tenha recebido a área já degradada, é responsável pela recuperação, se for o caso.

Quanto ao elemento normativo floresta, manifestouse desta forma o Superior Tribunal de Justiça:

O elemento normativo 'floresta', constante do tipo do injusto do art. 38 da Lei 9.605/98, é a formação arbórea densa, de alto porte, que recobre área de terras mais ou menos extensa. $\mathrm{O}$ elemento central é o fato de ser constituída por árvores de grande porte, Dessa forma, não abarca vegetação rasteira. (STJ, REsp 783652/SP, rel. Min. Felix Fischer, DJU 19.06.2006, p. 196)

A Corte também utiliza a definição de floresta tal qual a maioria dos doutrinadores brasileiros.

$\mathrm{Na}$ esfera penal, alterando posicionamento anterior, o Tribunal ampliou o seu entendimento quanto ao elemento normativo do art. 38 da Lei no 9.605/98, em decisão assim ementada:

PENAL. PROCESSUAL PENAL. HABEAS CORPUS. DENÚNCIA. IMPUTAÇÃO. CRIMES AMBIENTAIS PREVISTOS NOS ARTIGOS 38, 39, 40 E 48. 1. AÇÃO CIVIL PÚBLICA. RECONHECIMENTO DE OCORRENCIA DE
UMA ÚNICA CONDUTA. IRRELEVÂNCIA. INDEPENDÊNCIA ENTRE AS ESFERAS. 2. VEGETAÇÃO DO TIPO CAPOEIRA. DEVASTAÇÃO. POSSIBILIDADE DE ORIGINAR FLORESTA EM PROCESSO NATURAL. EXCLUSÃODOARTIGO38.IMPOSSIBILIDADE. HABEAS CORPUS. LIMITES ESTREITOS. 3. CONFLITO APARENTE ENTRE O ART. 38 E O ART. 39 DA LEI 9.605/98. CONCURSO MATERIAL. IMPOSSIBILIDADE. ART. 38 QUE JÁ ENGLOBA DANO DECORRENTE DE CORTE DE ÁRVORES. DIFERENÇA DE EXTENSÃO DO DANO. 4. ART. 40 DA LEI 9.605/90. TIPO PENAL. UNIDADES DE CONSERVAÇÃO. DANO. PARQUE ESTADUAL. PREVISÃO. 5. DENÚNCIA. INÉPCIA. DESCRIÇÃO ADEQUADA DA CONDUTA. REQUISITOS DO ARTIGO 41 DO CPP. OCORRÊNCIA. 6. LEI 9.099/90. DIREITO ADQUIRIDO AO PROCEDIMENTO. PROCEDIMENTO NÃO INICIADO. CRIME DE MENOR POTENCIAL OFENSIVO. INEXISTÊNCIA. 7. ORDEM CONCEDIDA.

1. O fato de haver sentença em ação civil pública reconhecendo a ocorrência de apenas uma das condutas imputadas não interfere no âmbito criminal, já que existe uma independência entre as duas esferas que viabiliza a valoração de um ilícito de formas diferentes.

2. A conduta de devastação de vegetação do tipo capoeira pode estar subsumida ao tipo penal previsto no artigo 38 da Lei 9.605/98, já que determinados tipos de capoeira permitem um processo de regeneração natural da floresta, caracterizando, portanto, "floresta em formação", daí porque não é viável o trancamento da ação penal via habeas corpus, se não é inequívoca a atipicidade.

3. É de ser reconhecido o excesso acusatório relativamente ao concurso material entre os artigo 38 e 39 da Lei 9.605/98, já que o artigo 38 engloba também a hipótese em que o dano à floresta de preservação permanente decorre do corte de árvores. 4. O dano a Parque Estadual está tutelado no âmbito do artigo 40 da Lei 9.605/98, que prevê como crime o dano às Unidades de Conservação, sejam de Proteção Integral, sejam de Uso Sustentável.

5. Inépcia da denúncia inocorrente, pois presentes os requisitos do artigo 41 do CPP, podendo-se identificar todas as circunstâncias necessárias à adequada individualização do fato. 6. Não há um direito adquirido ao procedimento previsto na Lei 9.099/90 se nenhum ato referente a ele chegou a ser realizado, tendo o paciente sido denunciado por crimes que extrapolam o limite conceitual dos crimes de menor potencial ofensivo.

7. Ordem concedida em parte, apenas para trancar a ação penal, excluindo-se da denúncia tão-somente a imputação relativa ao crime previsto no artigo 39 da Lei 9.605/98. 
Portanto, há a incidência do tipo penal previsto no art. 38 da Lei no 9605/98, mesmo que a área de preservação permanente não tenha formação arbórea densa e de alto porte, pois a capoeira foi considerada floresta em formação.

\section{CONCLUSÕES ARTICULADAS}

a) O meio ambiente está consagrado constitucionalmente como direito fundamental, para estas e futuras gerações. A legislação infraconstitucional determinou a proteção, em todas as esferas, das áreas de preservação permanente (APP), uma modalidade de espaço territorialmente protegido.

b) A Constituição Federal determinou a tutela também penal do meio ambiente, entendendo que a efetiva e gradual tutela do direito fundamental é bem jurídico a ser protegido. Esta é a função do Direito Penal contemporâneo. Há divergência doutrinária, mas prevalece este entendimento.

c) As áreas de preservação permanente (APP) têm função ambiental de proteção de diversos recursos, entre os quais, hídricos, do solo, da biodiversidade. Diante desta importante função, e com apenas uma destinação legal, não poderá ser utilizado, somente com expressa autorização.

d) O Direito Penal Ambiental tem sido considerado por diversos autores ${ }^{12}$ como um típico exemplo de direito penal simbólico. Não é estruturalmente capaz de lidar com os problemas ambientais, e é, assim, o uso ilegítimo de criminalização para obter efeitos meramente ilusórios.

e) O caráter acessório do Direito Penal Ambiental é tese forte, pois este não mantém uma função valorativa, mas puramente com a finalidade de estabelecer sanções de condutas e valores que se encontram nos restantes setores do ordenamento jurídico. Rodriguez Ramos denomina as relações do Direito Penal Ambiental com outros ramos do ordenamento jurídico, em especial o Direito Administrativo, como "sopreproteción de bienes jurídicos, que ya están protegidos de um modo más inmediato por otros sectores del ordenamiento jurídico (así, El medio ambiente, por lãs normas sectoriales administrativas de protección del médio ambiente)"13.

f) O Superior Tribunal de Justiça, alterando seu entendimento anterior, quanto ao elemento normativo do art. 38 da Lei no 9.605/98, admitiu que a área de preservação permanente não necessita ser de floresta densa e contínua, podendo ser ausente a formação arbórea densa e de alto porte, capoeira.

g) Correto o resultado da ação penal, aqui para fins meramente acadêmicos, nosso caso concreto, que absolveu os denunciados pelo delito previsto no art. 38 da Lei no 9.605/98, pois não definida, ainda, o que é "topo de morro", bem como não demonstrou a acusação de que a exploração de minerais não tinha licença.

\section{REFERÊNCIAS}

CARRAMENHA, Roberto. Direito da natureza. Campos do Jordão: Editora Mantiqueira, 1999.

COSTA, Helena Regina Lobo da. Proteção penal ambiental: Validade - efetividade - tutela por outros ramos do direito. São Paulo: Saraiva, 2010.

DOTTI, René Ariel. Incapacidade Criminal da Pessoa Jurídica: uma perspectiva do direito brasileiro. In: Responsabilidade Penal da Pessoa Jurídica: em defesa do princípio da imputação penal subjetiva. Coordenador Luiz Régis Prado. São Paulo: Revista dos Tribunais, 2001.

FARIA, Cássio Juvenal. Medidas provisórias e direito penal. In: Responsabilidade penal da pessoa jurídica e medidas provisórias e direito penal. São Paulo: Revista dos Tribunais, 1999.

FREITAS, Vladimir Passos de; FREITAS, Gilberto Passos de. Crimes contra a natureza. 9. ed. São Paulo: Revista dos Tribunais, 2012.

LEME MACHADO, Paulo Affonso. Direito ambiental brasileiro. São Paulo: Malheiros Editora, 1998.

LOPES JR, Aury. Direito processual penal. 9. ed. São Paulo: Saraiva, 2012.

ROXIN, Claus. A proteção dos bens jurídicos como função do Direito Penal. Trad. André Luís Callegari e Nereu José Giacomolli. 2. ed. Porto Alegre: Livraria do Advogado, 2009.

SIRVINSKAS, Luís Paulo. Tutela penal do meio ambiente. 4. ed. São Paulo: Saraiva, 2011.

TÁRRAGA, Maria Dolores Serrano et al. Tutela Penal Ambiental. Madrid: Dykinson, 2009.

\section{NOTAS}

1 René Ariel Dotti, contrário à responsabilização penal da pessoa jurídica, afirma que só a pessoa humana tem capacidade genérica de entender e querer, sendo a potencial consciência de ilicitude, isto é, a culpabilidade em si, uma qualidade exclusiva da pessoa física e impossível de ser encontrada no ente jurídico. Assim, por ser desprovida da capacidade de ação, a pessoa coletiva não seria, então, capaz de praticar uma conduta infratora, pois não poderia ser a ela atribuída a culpabilidade inerente à pessoa natural. In: DOTTI, René Ariel. Incapacidade Criminal da Pessoa
Jurídica: uma perspectiva do direito brasileiro. In: Responsabilidade Penal da Pessoa Jurídica: em defesa do princípio da imputação penal subjetiva. Coordenador Luiz Régis Prado. São Paulo: Revista dos Tribunais, 2001. p. 88 .

2 Pessoas jurídicas, que somente podem ser responsabilizadas criminalmente pelo permissivo do art. $225, \S 3^{\circ}$ da $\mathrm{CF} / 88$ : "as condutas e atividades consideradas lesivas ao meio ambiente sujeitarão os infratores, pessoas físicas ou jurídicas, a sanções penais e administrativas, independentemente de reparar os danos causados". Ocorre que, na verdade, a pessoa jurídica, na prática, mesmo na aplicação da lei de crimes 
ambientais, só sofre penalização nas esferas administrativa e civil; quando se fala em "punição"/sanção penal, propriamente dita, aqui considerada aquela restrição de liberdade, ou o cumprimento de "penas alternativas", serviços comunitários, etc., estes casos são aplicados tão somente ao administrador, ao gestor, aos agentes da pessoa jurídica, diretamente identificados como autores da ação danosa, ou por ela responsáveis. Até porque não se tira a liberdade (física) de uma empresa (que não pode ser "presa"). Ainda que a sanção penal possa se dar de outras formas que não apenas a restrição de liberdade, a partir do momento em que há impossibilidade de uma forma de aplicação (restrição de liberdade), penso que não estamos falando de Direito Penal na íntegra para pessoas jurídicas (em que pese alguns infratores ou criminosos, dependendo da gravidade da infração ou delito penal, também não merecerem pena de restrição de liberdade). $\mathrm{O}$ fato de o agente representante da empresa ser responsabilização não significa, necessariamente, penalização da empresa, que dependendo do caso poderá continuar exercendo suas atividades, salvo se cassado seu alvará.
3 TÁRRAGA, Maria Dolores Serrano et al. Tutela penal ambiental. Madrid: Dykinson, 2009, p. 37.

4 ROXIN, Claus. A proteção dos bens jurídicos como função do Direito Penal. Trad. André Luís Callegari e Nereu José Giacomolli. 2. ed. Porto Alegre: Livraria do Advogado, 2009, p. 14.

5 Idem, p. 15.

6 Ibidem, p. 17

7 Ibidem, p. 22

Ibidem, p. 54

9 Tutela penal ambiental. Madrid: Dykinson, 2009, p. 37

${ }^{10}$ Crimes contra a natureza. 9. ed. São Paulo: Revista dos Tribunais, 2012.

11 Tutela penal do meio ambiente. 4. ed. São Paulo: Saraiva, 2011.

${ }^{12}$ COSTA, Helena Regina Lobo da. Proteção penal ambiental: validade - efetividade - tutela por outros ramos do direito. São Paulo: Saraiva, 2010, p. 109.

13 RAMOS, Rodríguez. Compendio de Derecho Penal. Parte general. Madrid: Dykinson, 2006, p. 107. 